\title{
Dynamic Behaviour of Two-Phase Flow through a Flow Restricting Orifice
}

\author{
Olufemi Eyitope Bamidele, Christopher Vines, Wael Ahmed, Marwan Hassan \\ School of Engineering, University of Guelph, \\ 50 Stone Rd. E., Guelph, ON N1G 2W1 \\ obamidel@uoguelph.ca, vinesc@mail.uoguelph.ca, ahmedw@uoguelph.ca, mahassan@uoguelph.ca
}

\section{Extended Abstract}

Two-Phase flow through orifice is found in many industrial applications such as refrigeration, power generation, oil and gas, food and petrochemical industries. Orifices have been used for either metering or controlling the flow parameters in these systems. Evaluating the dynamic behavior of two-phase flow through orifices is extremely challenging due to the compressibility of the gas phase, deformable gas-liquid interface and the unsteady interactions between the phases. This dynamic behavior results in components failure caused by several degradation mechanisms such as flow induced vibration, flow accelerated corrosion, liquid impact erosion or cavitation erosion. Understanding the dynamics behavior of two-phase flow through such components is considered to be the key in order to design such systems. The present study aims at evaluating the main parameters that affect the system dynamics. The flow velocity and liquid turbulence were measured using Particle Image Velocimetry (PIV) and used to analyze the flow induced vibration in a horizontal pipe with a flow restricting orifice with an area ratio of 0.25 . Measurements of air-water two-phase pressure drop, void fraction and pipe displacement were also determined using pressure transducers, capacitance and optical displacement sensors respectively. Experiments were performed for air and water flow rates ranges between 0.007-0.057 1/s and 0.445 1/s-0.432 1/s respectively. The effect of two-phase flow redistribution, instantaneous void fraction on the tube vibration were experimentally investigated. Different dynamic behavior of tube vibration were classified for bubbly, stratified and slug flow patterns. Both the Frequency Response Function (FRF) and the modal analysis were found to describe the vibration properties of the system.

Keywords: Two-phase flow, Air-water, Dynamics, PIV, Flow induced vibration. 